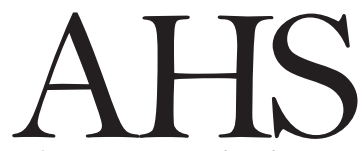

Advances in Horticultural Science

\title{
Strigolactone analogue GR24 reduces axillary bud out break and growth in tea tree, Melaleuca alternifolia (Maiden \& Betche) Cheel
}

\author{
G.E. Lowe ${ }^{(*)}$, M. Shepherd, T. Rose ${ }^{(*)}$, C. Raymond \\ Southern Cross Plant Science, Southern Cross University, P.O. Box 157, \\ Lismore, NSW 2480 Australia.
}

Key words: auxin, axillary bud release, shoot architecture, tea tree.

OPEN ACCESS

\begin{abstract}
${ }^{(*)}$ Corresponding author: g.lowe.22@student.scu.edu.au terry.rose@scu.edu.au
\end{abstract}

Citation:

LOWE G.E., SHEPHERD M., ROSE T., RAYMOND C., 2021 - Strigolactone analogue GR24 reduces axillary bud out break and growth in tea tree, Melaleuca alternifolia (Maiden \& Betche) Cheel. Adv. Hort. Sci., 35(4): 399-405

Copyright:

(C) 2021 Lowe G.E., Shepherd M., Rose T., Raymond C. This is an open access, peer reviewed article published by Firenze University Press (http://www.fupress.net/index.php/ahs/) and distributed under the terms of the Creative Commons Attribution License, which permits unrestricted use, distribution, and reproduction in any medium, provided the original author and source are credited.

Data Availability Statement:

All relevant data are within the paper and its Supporting Information files.

Competing Interests:

The authors declare no competing interests.

Received for publication 21 December 2020 Accepted for publication 12 August 2021

\begin{abstract}
Strigolactone acts with other plant hormones to influence shoot architecture by suppressing axillary bud outgrowth. The exogenous application of synthetic analogues of strigolactone, such as GR24, have been investigated as a way to manage plant architecture in a number of crops. In this study we test whether GR24 can be used to supress bud outgrowth in clonal propagules of tea tree (Melaleuca alternifolia) in order to retain a "single stem" form desirable for machine planting. GR24 was applied to decapitated rooted cuttings of tea tree at two rates $\left(0.5 \mathrm{mg} \mathrm{L}^{-1}\right.$ and $\left.1.5 \mathrm{mg} \mathrm{L}^{-1}\right)$, with and without auxin. By 21 days post -treatment, GR24 at both rates had significantly $(p<0.05)$, reduced the mean number of axillary buds $(5.7 \pm 0.4$ and $5.5 \pm 0.3$ buds respectively) compared to decapitated untreated control plants $(8.9 \pm 0.6$ buds). Suppression of buds was significantly higher again when auxin was applied in conjunction with GR24. Nonetheless, no exogenous hormone treatment was as effective at suppressing bud outgrowth as the apical dominance that occurred in intact control plants (1.1 \pm 0.4 buds).
\end{abstract}

\section{Introduction}

Tea tree, Melaleuca alternifolia (Maiden \& Betche) Cheel, is a small tree, native to the subtropics of eastern Australia (ANPSA, 2012), which is cultivated in plantations for the production of a medicinally valuable essential oil (Carson et al., 2006). The Australian industry has developed around improved cultivars released as seed lines, but there is recognition that clonal deployment should offer advantages in plantation uniformity and productivity (Doran et al., 1997). Although tea tree has been regarded as relatively easy to propagate by cloning (Shepherd et al., 2013), the production of high quality propagules with the desired form compatible with automated machine planters remains a challenge.

Tea tree tip cuttings with single stem architecture suitable for mechanical planting can be produced if the apical bud remains intact (Lowe et al., 2019). Nodal cuttings (apical tips removed) are preferred to tip cuttings by 
some propagators for their robustness in the nursery but these tend to have a multi-stem habit which is unsuitable for machine planting as the "bushy" shoots get stuck in the delivery tubes of planters. Form-pruning of propagules prior to planting may be one way to overcome this compatibility issue, but this is labour intensive and costly on a large scale.

Shoot architecture is a consequence of complex interplay of interacting plant hormonal signals involving auxin, cytokinin (CK) and strigolactone (SL) that regulate bud release and/or subsequent growth (Ferguson and Beveridge, 2009; Leyser, 2009). Auxin is produced in the shoot apex and is actively transported down the stem, restricting bud release. Auxin does not enter the axillary buds but indirectly impacts on bud release by inhibiting auxin export from axillary buds and by regulating stem CK and SL to either promote or suppress branching, respectively (Gomez-Roldan et al., 2008; Muller and Leyser, 2011; Dun et al., 2012).

The influence of SL upon plant architecture was unravelled with the aid of studies on mutants with increased branching, including the ramosus (rms) mutant in pea (Pisum sativum L.), and the more axillary growth (max) mutant in Arabidopsis (Arabidopsis thaliana L.) (Brewer et al., 2009; Dun et al., 2013). Mutants have exaggerated branching habits relative to wild type plants because they are deficient in SL due to genetic changes in transcription or hormonal pathways (Umehara et al., 2008; Yaish et al., 2010). Potential horticultural applications of SL include, management of plant architecture and control of fruit ripening, although high cost of SL production and regulatory approvals remain a limitation to large scale commercial use (Vurro et al., 2016; Ferrero et al., 2018).

In this study we investigated the use of exogenous hormones to manage shoot form of tea tree cuttings during propagation. The aim was to test whether application of an exogenous synthetic SL, GR24, or a combination of GR24 and auxin, can suppress axillary bud release in tea tree. Suppression by SL was studied in decapitated plants where axillary bud outgrowth was triggered by removal of the apical bud.

\section{Materials and Methods}

\section{Plant growth environment and reagents}

Experiments were conducted at Southern Cross University, Lismore Campus, NSW, Australia during
2020, inside controlled environment growth cabinets, under $16 / 8$ hour photoperiod, and with temperature set at $26^{\circ} \mathrm{C}$. Stock hormone solutions were prepared by following Brewer et al. (2009) for indole -3 acetic acid (IAA), and Manandhar (2016) for GR24. Working solutions of $1.75 \mathrm{mg} \mathrm{L}^{-1}(10 \mu \mathrm{M})$ for IAA, and $0.5 \mathrm{mg} \mathrm{L}^{-1}(1.68 \mu \mathrm{M})$, and $1.5 \mathrm{mg} \mathrm{L}^{-1}(5 \mu \mathrm{M})$ for GR24, were prepared by dilution with distilled water and stored at $4^{\circ} \mathrm{C}$.

\section{Method and reagent validation using pea plants}

Initial tests were carried out using the $P$. sativum type rms1 mutant (provided by Professor C. Beveridge, University of Queensland, Australia) to confirm competency of reagents and methods in our laboratory. Testing of mutant pea followed methods of Manandhar, (2016). Application of $0.3 \mathrm{mg} \mathrm{L}^{-1}$ and 1 $\mathrm{mg} \mathrm{L}^{-1} \mathrm{GR} 24$ to the rms1 mutant of pea significantly reduced side branching compared to the untreated rms 1 control, thus validating the method in our laboratory.

\section{Testing GR24 applications on tea tree}

The experiment used a Randomised Complete Block Design, with four blocks (replicates) of five plants in line plots, subject to one of six treatments (four hormone or two control treatments, giving a total of 120 plants). Plants subject to hormone treatments either had a low or high treatment of GR24 (0.5 mg L-1 or $1.5 \mathrm{mg} \mathrm{L}^{-1}$ ) with or without supplemental IAA (1.75 $\left.\mathrm{mg} \mathrm{L}^{-1}\right)$. Control treatments consisted of decapitated plants, and plants with an intact apex in distilled water.

Scion from a clonal line was set in January 2020 using the mini cutting technique with intact apical buds (Lowe et al., 2019). The GR24 experiments were conducted 5 months post-setting when cuttings had rooted and possessed a single main stem with no visible axillary buds detectable with a 10x magnification hand lens (Fig. 1 left). Roots were washed free of media and trimmed to $5 \mathrm{~cm}$ in length. Except for control plants, the shoot apex was removed (approximately $2 \mathrm{~cm}$ ) above node 35 (counted basipetaly from the lowest detectable node) to provoke release from apical dominance (Thimann and Skoog, 1934). All plants were then positioned upright in clear $50 \mathrm{~mL}$ Falcon tubes containing $5 \mathrm{~mL}$ of treatment solution, or distilled water, so that only the roots were in contact with treatment solutions (Fig. 1 middle).

The experiment was conducted over 21 days in June 2020. Treatment solutions were applied on day 1 and replaced every 7 days. For plants subjected to a 

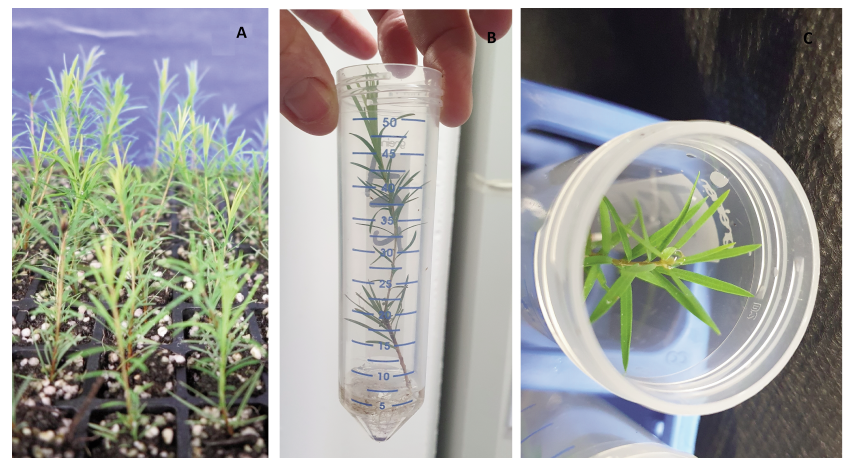

Fig. 1 - Preparing rooted cuttings of tea tree M. alternifolia for the GR24 experiment (left); A rooted cutting five months after setting and prior to decapitation (middle); Rooted cutting (control intact) in $50 \mathrm{~mL}$ clear plastic tube at the beginning of the experiment, and (right) a droplet of IAA applied on top of decapitated stem stump in GR24 and IAA.

hormone combination treatment (GR24 and IAA), a $0.5 \mathrm{~mL}$ droplet of IAA was placed on top of the decapitated stem to simulate the presence of the shoot apex and natural auxin production (Cline, 1996) (Fig. 1 right). All plants were given $1 \mathrm{~mL}$ of Yoshida nutrient solution (Yoshida et al., 1976) 2 days before treatment solutions, in order to promote growth.

\section{Data collection and analysis}

The number of visible axillary buds and axillary shoot length for the 10 uppermost nodes (nodes 1 to 10 , with 1 being furthest from the roots) on each plant was recorded at the same time on day 2, 5, 7, $9,12,14,16,19$, and 21 . Shoot length was determined to the nearest $\mathrm{mm}$ with digital callipers. Oneway analysis of variance (ANOVA) was used to test for treatment effects on the number of axillary buds and shoot growth. Where treatment effects were significant $(p<0.05)$, a Duncan's multiple range test was performed on treatment means. All statistical analyses were performed using Genstat, Release 19.1 (VSN International, 2018).

\section{Results}

Effects of GR24 on axillary bud growth in tea tree Rates of bud release over a 21 day time course experiment

Treatment effect was significant at each of the 9 days counts were undertaken $(p<0.05)$ (Fig. 2). No buds were detected on control intact plants until Day 9 , and only $40 \%$ of control intact plants had one or more detectable buds by 21 days post-treatment (Fig. 2). The rate of bud release on control intact plants was due to normal hormonal regulation in rooted cuttings of tea tree, and it established a baseline for the slowest and least degree of axillary bud development in this study (Fig. 2). In contrast, control decapitated plants had the highest rate of bud development of any of the six treatments as bud release was not mitigated by normal endogenous regulation or due to the presence of exogenous hormonal treatment (Fig. 2). The axillary buds on control decapitated plants began to initiate 2 days after decapitation and continued to develop for the duration of the experiment, with significantly more buds detected at each recording date than any other treatment (Fig. 2). Where exogenous hormones were applied (either

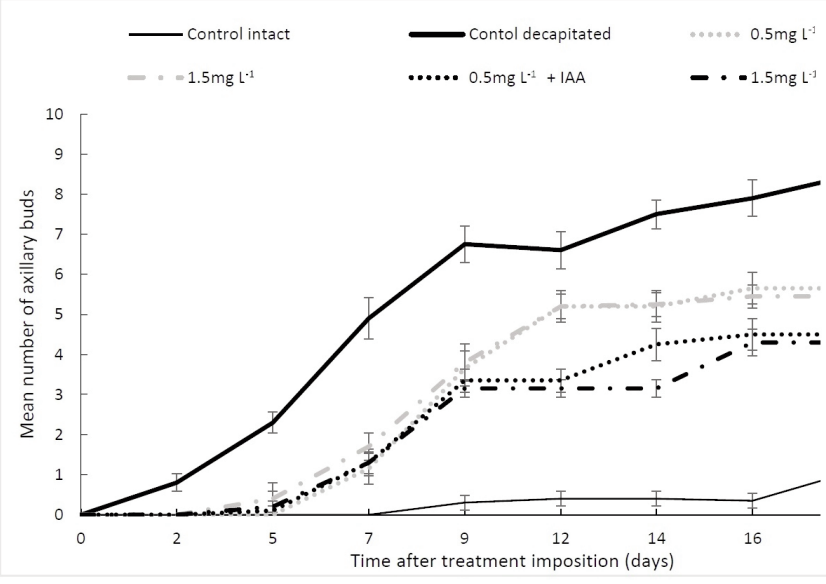

Fig. 2 - Mean number of detectable axillary buds over a 21-day time course for tea tree M. alternifolia propagules subjected to GR24 or GR24 plus IAA compared to control intact and decapitated plants. Error bars represent SE of means.

GR24, or GR24 + IAA) the bud numbers were intermediate to the control intact and control decapitated extremes (Fig. 2). All four hormone treatments tended to track together until Day 9, but thereafter, the additional action of auxin apparently moderated the detectable number of buds further (Fig. 2). There was no difference in the number of detectable buds between the low and high GR24 treatment, regardless of IAA presence (Fig. 2).

At the end of the 21-day time course experiment, the control intact plants had significantly less buds (mean + SE $1.1 \pm 0.4)$, and control decapitated plants had a significantly more buds (mean + SE $8.9 \pm 0.6$ ), than all other treatments (Fig. 2). While the rate of GR24 (high versus low) had no effect, the addition of 
auxin with GR24 resulted in significantly fewer buds relative to GR24 at either rate alone (Fig. 2).

Size and patterns of bud development along the stem

When considering all assessed axillary buds (pooled data from all 10 nodes), as measured on Day 21 , hormone treatments of GR24, or GR24 + IAA, significantly reduced the bud size compared to control decapitated plants $(p<0.05)$ (Table 1$)$. The average bud length for hormone treatments ranged between $2.5 \pm 0.5 \mathrm{~mm}$ and $3.3 \pm 0.9 \mathrm{~mm}$ and was significantly less than the average for control decapitated plants $(4.2 \pm 0.6 \mathrm{~mm})$, and significantly higher than for control intact plants $(0.03 \pm 0.08 \mathrm{~mm}$ ) (Table 1$)$.

Assessment of bud development node by node revealed further differences in developmental patterns. On control intact plants, buds on the uppermost nodes (nodes 1 to 3 ), if present, were not of a measurable size. In control decapitated plants, buds were longest in the upper most few nodes, and gradually reduced in size to the lowest measured node (node 10) (Table 1). In hormone treated plants, the longest buds occurred at the uppermost nodes (node 2 was generally longer than node 1 ), and again there was a progressive decline in size moving down the stem (Table 1). Bud length was not typically shorter in hormone treated plants relative to control decapitated plants at the uppermost nodes, but below node 5 , hormone treated plants tended to have significantly shorter buds (Table 1). A representative example of the budding response showing bud position and length is presented in figure 3 .

\section{Discussion and Conclusions}

Strigolactone suppressed axillary bud growth in tea tree

Relative to control decapitated plants without GR24 application, application of a synthetic strigolactone analogue, GR24, at rates of $0.5 \mathrm{mg} \mathrm{L}^{-1}$ or $1.5 \mathrm{mg}$ $\mathrm{L}^{-1}$, suppressed axillary bud number and expansion in decapitated rooted cuttings of tea tree. This response was consistent with its effects on other species such as calla lily (Zantedeschia L. sp.) (Manandhar, 2016) where synthetic SL GR24 was typically applied at concentrations between $0.3 \mathrm{mg} \mathrm{L}^{-1}(1 \mu \mathrm{M})$ and $3 \mathrm{mg} \mathrm{L}^{-1}$ (10 $\mu \mathrm{M})$ (Umehara et al., 2008; Manandhar, 2016). Where larger plants at later stages of ontogenetic development (i.e. reproductive maturity) were studied, such as the study of Chrysanthemum morifolium Ramat, rates as high as $15 \mathrm{mg} \mathrm{L}^{-1}(50 \mu \mathrm{M})$ were required to inhibit bud growth (Dierck et al., 2016). A moderate response was evident in our tea tree plants at dosages towards the lower end of those used previously with herbaceous species. Both tested rates gave a similar response and, a synergistic effect between SL and auxin was evident, so that bud outgrowth was significantly reduced relative to the application of SL alone. A further factor that may have contributed to the efficacy of the treatments in our study, may have been the retention of the root system. SL is synthesised both in the roots and the shoots and is transported acropetally to suppress bud outgrowth (Domagalska and Leyser, 2011). In most other studies, stem sections with roots

Table 1 - Mean length of the axillary buds from node 1 to node 10 measured at day 21 . Treatment effect was tested on an individual node basis

\begin{tabular}{|c|c|c|c|c|c|c|}
\hline & Control intact & $\begin{array}{l}\text { Low GR24 } \\
\left(0.5 \mathrm{mg} \mathrm{L}^{-1}\right)\end{array}$ & $\begin{array}{l}\text { High GR24 } \\
\left(1.5 \mathrm{mg} \mathrm{L}^{-1}\right)\end{array}$ & $\begin{array}{c}\text { Low GR24+IAA } \\
\quad\left(0.5 \mathrm{mg} \mathrm{L}^{-1}\right)\end{array}$ & $\begin{array}{l}\text { High GR24+IAA } \\
\qquad\left(1.5 \mathrm{mg} \mathrm{L}^{-1}\right)\end{array}$ & $\begin{array}{c}\text { Control } \\
\text { decapitated }\end{array}$ \\
\hline Average growth (mm) & $0.03 \pm 0.08 a$ & $2.5 \pm 0.5 b$ & $3.3 \pm 0.9 b$ & $2.7 \pm 0.6 b$ & $2.7 \pm 0.6 b$ & $4.2 \pm 0.6 c$ \\
\hline Node 1 (uppermost) & $0 \mathrm{a}$ & $7.1 \pm 1.1 b$ & $9.8 \pm 1.2 b c$ & $9.2 \pm 1.5 b c$ & $9.4 \pm 1.1 b c$ & $12 \pm 1.3 c$ \\
\hline Node 2 & $0 \mathrm{a}$ & $8.7 \pm 1.1 b$ & $10.5 \pm 1.1 \mathrm{bc}$ & $9.4 \pm 1.3 b c$ & $10.1 \pm 0.9 \mathrm{bc}$ & $12 \pm 0.8 c$ \\
\hline Node 3 & $0 \mathrm{a}$ & $5.4 \pm 0.9 \mathrm{bc}$ & $7.4 \pm 1.0 \mathrm{c}$ & $4.2 \pm 0.9 b$ & $4.5 \pm 1.1 b$ & $7.2 \pm 0.8 c$ \\
\hline Node 4 & $0.03 \pm 0.03 a$ & $2.1 \pm 0.9 b$ & $3.2 \pm 0.7 b c$ & $2.7 \pm 0.9 \mathrm{bc}$ & $1.6 \pm 0.5 \mathrm{ab}$ & $4.6 \pm 0.9 c$ \\
\hline Node 5 & $0.1 \pm 0.1 \mathrm{a}$ & $0.8 \pm 0.3 a$ & $1.3 \pm 0.4 \mathrm{a}$ & $0.8 \pm 0.3 a$ & $1.2 \pm 0.4 \mathrm{a}$ & $2.8 \pm 0.7 b$ \\
\hline Node 6 & $0.1 \pm 0.1 \mathrm{a}$ & $0.2 \pm 0.05 a$ & $0.7 \pm 0.3 a$ & $0.1 \pm 0.1 \mathrm{a}$ & $0.4 \pm 0.2 \mathrm{a}$ & $1.4 \pm 0.5 b$ \\
\hline Node 7 & $0.1 \pm 0.1 \mathrm{ab}$ & $0.4 \pm 0.3 b c$ & $0.1 \pm 01 a b$ & $0.1 \pm 0.04 a b$ & $0 \mathrm{a}$ & $0.7 \pm 0.2 c$ \\
\hline Node 8 & $0.03 \pm 0.03 a$ & $0.6 \pm 0.4 b$ & $0.1 \pm 0.3 a$ & $0.03 \pm 0.03 a$ & $0 \mathrm{a}$ & $0.5 \pm 0.1 b$ \\
\hline Node 9 & $0 \mathrm{a}$ & $0.1 \pm 0.1 \mathrm{a}$ & $0 \mathrm{a}$ & $0.03 \pm 0.03 a$ & $0 \mathrm{a}$ & $0.2 \pm 0.1 b$ \\
\hline Node 10 (lower most) & $0.1 \pm 0.1 \mathrm{a}$ & $0.03 \pm 0.03 a$ & $0 \mathrm{a}$ & $0 \mathrm{a}$ & $0 \mathrm{a}$ & $0.2 \pm 0.1 b$ \\
\hline
\end{tabular}

Treatment means followed by the same letter within the same row are not significantly different at the $95 \%$ confidence level (- denotes no bud present). 

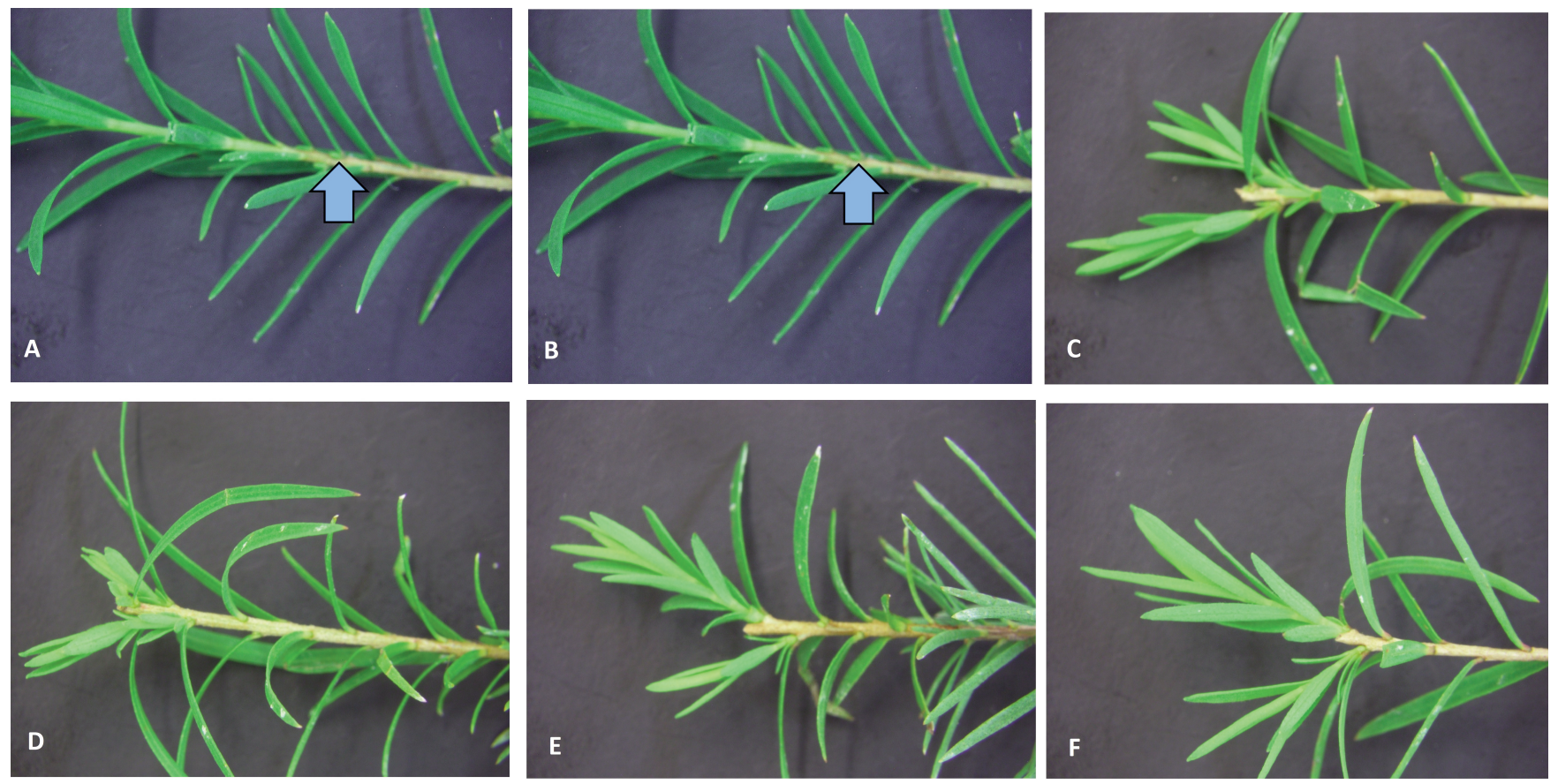

Fig. 3 - A representative M. alternifolia propagule from each treatment showing the pattern and size of axillary buds 21 days after treatment. Figure 3a, is a control intact propagule, buds were not visible without magnification at the upper nodes. Buds were visible from node 4 or lower but did not develop (arrow). Figure 3b, is a control decapitated propagule, with axillary buds at upper nodes developed into side shoots (arrow). Figures $3 \mathrm{c}$ to $3 \mathrm{f}$ show a propagule from each of the GR24 and GR24 plus IAA treatments, buds and developing side shoots visible only on the upper most nodes with generally less shoot growth compared to the control decapitated propagule in figure $3 b$.

removed were used for experimentation, and SL was supplied to the basal stem stump. Therefore endogenous SL may have reinforced any effect due to exogenous GR24 in our case, potentially inducing a stronger (bud outgrowth inhibition) response in the lower range of concentrations of GR24 compared to studies on other plants.

\section{Axillary bud outgrowth further inhibited with the} addition of an auxin supply

When GR24 was applied in conjunction with auxin, suppression of axillary bud outgrowth was enhanced relative to exogenous GR24 alone, as reported in other species (Crawford et al., 2010; Liang et al., 2010; Ward et al., 2013). Liang et al. (2010) reported total inhibition of bud outgrowth when $1.5 \mathrm{mg} \mathrm{L}^{-1}(5 \mu \mathrm{M})$ of GR24 and NAA were applied to chrysanthemum (Dendranthema grandiflorum) stems. Although both GR24 and GR24 plus IAA (at the low and high rate) treatments inhibited bud outbreak in tea tree plants for 5 days, when the buds began to grow and elongate, the growth rate of the buds was comparable to the control decapitated plants, at least for the upper four nodes for most plants (Table 2). These observations provide further support for the influence of auxin in the vascular stream of the main stem on bud release and the influence of auxin transport on SL inhibition of axillary buds. Ultimately, our findings are consistent with both the canalisation (Brewer et al., 2009; Ljung et al., 2001) and second messenger (Domagalska and Leyser, 2011) models developed to explain the physiological regulation of shoot architecture involving the interaction plant hormones including auxin, CK and SL (Gomez-Roldan et al., 2008; Domagalska and Leyser, 2011).

\section{Competition between buds}

The role of the GR24 in reducing bud release and growth needs to be considered along with the inhibitory effect active buds have on buds above or below it and those opposite to it (Thimann and Skoog, 1934). Lateral buds do not produce auxin while they remain dormant but produce considerable quantities when actively growing (Balla et al., 2011). Auxin synthesised in an active bud is transported into 
the main stem, and this auxin saturation prevents auxin movement out of axillary buds further down the stem, inhibiting bud growth (Leyser, 2005; Balla et al., 2011). Tea tree plants treated with GR24 or GR24 + IAA, buds tended to form on the upper nodes (node 1 to node 10), whereas buds formed down to node 14 on control decapitated plants (Table 1; data $>$ node 10 not shown). The rapidly growing buds on the upper nodes of control decapitated plants did not appear to inhibit bud release on the nodes below them, but they did affect subsequent bud elongation, consistent with a requirement for SL for bud inhibition (Beveridge, 2000). The mean length of the buds on the control decapitated plants decreased significantly for the majority of nodes, basipetally $(p<0.05)$ (Table 1). For plants given the higher rates of GR24 (with and without IAA), active buds may have contributed to the suppression of bud outbreak on the lower nodes, as no bud outbreak occurred past node 6 and 8, for GR24 and GR24 +IAA respectively (Table $1)$.

Implications for use of SL analogues as agents for manipulating tea tree nursery stock

This study demonstrated the potential of synthetic SL GR24 at relatively low concentrations of $0.5 \mathrm{mg}$ $\mathrm{L}^{-1}$ and $1.5 \mathrm{mg} \mathrm{L}^{-1}$ to suppress bud outgrowth in tea tree. This was encouraging for a potential application of SL in an early intervention response to mitigate undesirable side branching of plants where shoot tips are inadvertently lost due to pest, heat or desiccation damage, or where tips are removed during propagation (i.e. use of nodal cuttings). None of the artificial treatments tested were as effective as the control intact treatment where apical dominance suppresses bud outgrowth, but a moderate response at relatively low dosages, suggests there is room to explore whether higher dosages can elicit stronger suppression of side branching. For example, Liang et al., (2010) found higher concentrations of exogenous SL or SL with auxin suppressed bud outgrowth to the same degree as endogenous regulation induced by an intact apical buds in chrysanthemum.

The response at lower dosages in this first investigation was also encouraging because woody perennial species do not appear to be recalcitrant to the influence of hormones, at least for our relatively small (less than 2 grams fwt of biomass) test plants, with root systems, and with low tissue specialisation (i.e. stems had low degrees of lignification and had not formed papery bark). Further work will be required, however, to establish the efficacy of higher dosages to elicit stronger suppression responses in nursery propagules, the longevity of the effect of exogenous SL on the form of the propagule (i.e. does it persist to suppress side shoots on larger plants ready for release from the nursery?), and whether there is any unfavourable longer term impact of plant growth in the field.

\section{Acknowledgements}

The authors thank Professor Christine Beveridge of the University of Queensland for supply of rms1 pea ( $P$. sativa L.) seeds. This study was supported by funding from through the Cooperative Research Centre Project scheme for Project P53955 "Enhanced market agility for the Australian tea tree oil industry".

\section{References}

ANPSA 2012 - Melaleuca, Propagation. - Australian Native Plant Society Australia. http://www.anpsa.org. au/melaleu2.html.

BALLA J., KALOUSEK P., REINOHL V., FRIML J., PROCHAZKA S. 2011 - Competitive canalization of PIN-dependent auxin flow from axillary bud controls pea bud outgrowth. - The Plant J., 65: 571-577.

BEVERIDGE C.A., 2000 - Long-distance signalling and mutational analysis of branching in pea. - J. Plant Growth Regul., 32: 193-203.

BREWER P.B., DUN E.A., FERGUSON B.J., RAMEAU C., BEVERIDGE C.A., 2009 - Strigolactone acts downstream of auxin to regulate bud outgrowth in pea and Arabidopsis. - Plant Physiol., 150: 482-493.

CARSON C.F., HAMMER K.A., RILEY T.V., 2006 - Melaleuca alternifolia (Tea tree) oil: a review of antimicrobial and other medicinal properties. - Amer. Soc. Microbio., 19(1): 50-62.

CLINE M.G., 1996 - Exogenous auxin effects on lateral bud outgrowth in decapitated shoots. - Ann. Bot., 78(2): 255-266.

CRAWFORD S., SHINOHARA N., SIEBERER T., WILLIAMSON L., GEORGE G., HEPWORTH J., MULLER D., DOMAGALSKA M., LEYSER O., 2010 - Strigolactones enhance competition between shoot branches by dampening auxin transport. - Develop., 137: 2905-2913.

DIERCK R., DE KEYSER E., DE RIEK J., DHOOGGHE E., VAN HUYLENBROECK J., PRISEN E., VAN DER STRAETEN D., 2016 - Change in auxin and cytokinin levels coincides with altered expression of branching genes during axillary bud outgrowth in Chrysanthemum. PLoS ONE 11:e0161732. 
DOMAGALSKA M., LEYSER O., 2011 - Signal integration in the control of shoot branching. - Nat. Rev. Mol. Cel. Biol., 12: 211-221.

DORAN J.C., BAKER G.R., MURTAG G.J., SOUTHWELL I.A., 1997 - Improving tea tree yield and quality through breeding and selection. - Report for the RIDC, Canberra, pp. 1-50.

DUN E.A., DE SAINT G.A., RAMEAU C., BEVERIDGE C.A., 2012 - Antagonistic action of strigolactone and cytokinin in bud outgrowth control. - Plant Physiol., 158(1): 487-498.

DUN E.A., DE SAINT G.A., RAMEAU C., BEVERIDGE C.A., 2013 - Dynamics of strigolactone function and shoot branching responses in Pisum sativum. - Mol. Plants, 6: 128-140.

FERGUSON B.J., BEVERIDGE C.A., 2009 - Roles of auxin, cytokinin, and strigolactone in regulating shoot branching. - Plant Physiol., 149: 1929-1944.

FERRERO M., PAGLIARANI C., NOVÁK O., FERRANDINO A., CARDINALE F., VISENTIN I., 2018 - Exogenous strigolactone interacts with abscisic acid-mediated accumulation of anthocyanins in grapevine berries. - J. Exp. Bot., 69: 2391-2401.

GOMEZ-ROLDAN V., FERMAS S., BREWER P.B., PUECHPAGES V., DUN E.A., PILLOT J.P., LETISSE F., MATUSOVA R., DANOUN S., PORTAIS J.C., BOUWMEESTER H., BECARD G., BEVERIDGE C.A., RAMEAU C., ROCHANGE S.F., 2008 - Strigolactone inhibition of shoot branching. - Nature, 455: 189-194.

LEYSER O., 2005 - The fall and rise of apical dominance. Curr. Opin. Genet. Dev., 15(4): 468-471.

LEYSER O., 2009 - The control of shoot branching: an example of plant information processing. - Plant Cell Environ., 32: 694-703.

LIANG J., ZHAO L., CHALLIS R., LEYSER O., 2010 Strigolactone regulation of shoot branching in chrysanthemum (Dendranthema grandiflorum). - J. Exper. Bot., 61(11): 3069-3078.

LJUNG K., RISHIKESH P., SANDBERG G., 2001 - Sites and homeostatic control of auxin biosynthesis in
Arabidopsis during vegetative growth. - Plant J., 28(4): 465-474.

LOWE G.E., SHEPHERD M., ROSE T., RAYMOND C., 2019 Mini cuttings improve the shoot and root architecture of tea tree, Melaleuca alternifolia (Maiden \& Betche) Cheel. - Propag. Ornam. Plants, 19(4): 95-105.

MANANDHAR S., 2016 - Strigolactones and hormonal interaction in control of branching in Zantedeschia and other horticultural species. - PhD Thesis, Massey University, Palmerston North, New Zealand, pp. 228.

MULLER D., LEYSER O., 2011 - Auxin, cytokinin and the control of shoot branching. - Ann. Bot., 107: 1203-1212.

SHEPHERD M., ROSE T., RAYMOND C., 2013 - Rejuvenation of mature native tea tree (Melaleuca alternifolia (Maiden \& Betche) Cheel. for vegetative propagation. Propag. Ornam. Plants, 13: 103-111.

THIMANN K.V., SKOOG F., 1934 - On the inhibition of bud development and other functions of growth substance in Vicia faba. - Proc. Royal. Soc. B., 114: 317-339.

UMEHARA M., HANADA A., YOSHIDA S., AKIYAMA K., ARITE T., TAKEDA-KAMIYA N., MAGOME H., KAMIYA Y., SHIRASU K., YONEYAMA K., KYOZUKA J., YAMAGUCHI S., 2008 - Inhibition of shoot branching by new terpenoid plant hormones. - Nature, 455: 195-200.

VSN International, 2018 - Genstat for Windows $19^{\text {th }}$ Edition. - VSN Int. I, Hemel Hempstead, UK.

VURRO M., PRANDI C., BAROCCIO F., 2016 - Strigolactones: how far is their commercial use for agricultural purposes? - Pest Manag., 72: 2026-2034.

WARDS P., SALMON J., HANLEY S.J., KARP A., LEYSER O., 2013 - Using Arabidopsis to study shoot branching in biomass willow. - Plant Physiol., 162: 800-811.

YAISH M.W.F., GUEVARA D.R., EL-KEREAMY A., ROTHTSEIN S.J., 2010 - Axillary shoot branching in plants, pp. 3752. - In: PUA E.C., and M.R. DAVEY (eds.) Plant developmental biology. Biotechnological perspectives. Springer-Verlag Berlin, Heidelberg, Germany, pp. 485.

YOSHIDA S.I., FORNO D.A., COCK J.H., GOMEZ K.A., 1976 Laboratory manual for physiological studies of rice. Inter. Rice Research Institute, Manila, Philippines. 
